NASA Technical Memorandum 100428

\title{
Development of a Mobile Research Flight Test Support Capability
}

\section{Donald C. Rhea and Archie L. Moore}

(NASA-TH-100428) DEVELOPHENT OF A MOBILE BESEARCH FLIGHT TEST SUPPORT CAPABILITY (NASA) $12 \mathrm{p}$
CSCL $14 \mathrm{~B}$
N $88-22883$

Unclas

0142339

May 1988 
NASA Technical Memorandum 100428

\section{Development of a Mobile Research Flight Test Support Capability}

Donald C. Rhea and Archie L. Moore

Ames Research Center, Dryden Flight Research Facility, Edwards, California

National Aeronautics and

Space Administration

Ames Research Center

Dryden Flight Research Facility

Edwards, California 93523-5000 


\title{
DEVELOPMENT OF A MOBILE RESEARCH FLIGHT TEST SUPPORT CAPABILITY
}

\author{
Donald C. Rhea* and Archie L. Moore ${ }^{\dagger}$ \\ NASA Ames Research Center \\ Dryden Flight Research Facility \\ Edwards, California
}

\begin{abstract}
This paper presents the approach taken by the NASA Western Aeronautical Test Range (WATR) of the Ames Research Center (ARC) to develop and utilize mobile systems to satisfy unique realtime research flight test requirements of research projects such as the advanced fighter technology integration (AFTI) F-16, YAV-8B Harrier, F-18 high-alpha research vehicle (HARV), XV-15, and the UH-60 Black Hawk. The approach taken is cost-effective, staff efficient, technologically current, and provides a safe and effective research fight test environment to support a highly complex set of real-time requirements including the areas of tracking and data acquisition, communications (audio and video) and real-time processing and display, postmission processing, and command uplink. The development of this capability has been in response to the need for rapid deployment at varied site locations with full real-lime computations and display capability. This paper will discuss the requirements, implementation and growth plan for mobile systems deveiopment within the NASA Western Aeronautical Test Range.
\end{abstract}

\section{Nomenclature}

$\begin{array}{ll}\text { AFTI } & \text { advanced fighter technology integration } \\ \text { ARC } & \text { Ames Research Center } \\ \text { bps } & \text { bits/sec } \\ \text { CRT } & \text { cathode ray tube } \\ \text { dbm } & \text { decibels in relation to milliwatts } \\ \text { DFRF } & \text { Dryden Flight Research Facility } \\ \text { EIRP } & \text { effective isotropic radiated power } \\ \text { GSFC } & \text { Goddard Space Flight Center } \\ \text { HARV } & \text { high-alpha research vehicle } \\ \text { kbps } & \text { kbit/sec } \\ \text { Mbps } & \text { Mbit/sec } \\ \text { MCC } & \text { mission control center } \\ \text { MFFC } & \text { Moffctt Field Flight Complex } \\ \text { MMFTS } & \text { mobile multifrequency tracking system }\end{array}$

NASA National Aeronautics and Space Administration

\footnotetext{
"Deputy WATR Manager.

'Flight Test Information Systems Branch Chief. Member AIAA.
}

$\begin{array}{ll}\text { NASP } & \text { national aerospace plane } \\ \text { PCM } & \text { pulse code modulation } \\ \text { PI } & \text { principle investigator } \\ \text { POCC } & \text { project operations control center } \\ \text { PTAPS } & \text { parallel telemetry and processing system } \\ \text { RAM } & \text { random access memory } \\ \text { RPRV } & \text { remotely piloted research vehicle } \\ \text { WATR } & \text { Western Aeronautical Test Range } \\ \text { WFF } & \text { Wallops Flight Facility }\end{array}$

\section{Introduction}

Complex real-time requirements continue to challenge systems development at NASA Ames Research Center, Western Aeronautical Test Range (WATR). Innovative systems designs by the WATR development teams at Ames Research Center, Moffett Field, California, and Dryden Flight Research Facility (DFRF), Edwards Air Force Base, California, continue to push technology limits. These systems provide the foundation for the WATR contribution to the success of the NASA aeronautics programs and a basis for the future development of advanced ground-based systems.

The primary mission of the WATR is to provide a capability to conduct aeronautical flight research missions through the development and operation of tracking and data acquisition systems, realtime processing and display systems, and audio and video communications systems (Fig. 1). This development has been limited to sites at three geographic locations within California: Ames Research Center, Dryden Flight Research Facility, and Naval Auxiliary Landing Field, Crows Landing. The limitation as to a fixed location has been overcome with the development of a mobile research flight test support capability.

The capability required to support mobile research flight test includes development and operation of radar and telemetry tracking systems, real-time processing and display systems, communications systems (audio and video), postmission processing, remotely piloted research vehicle (RPRV) cockpit and systems, and command uplink - all in a minimal amount of space with self-contained power and environmental control. The evolution of this capability (Fig. 2) demonstrated its feasibility and benefits. This paper will review the requirements, implementation, and growth plan for this mobile research flight test support capability. 


\section{Aeronautics Requirements}

Specific requirements for individual research flight test activities vary extensively between vehicles and individual missions. All aeronautics programs have generic requirements for tracking the vehicle for space position and downlink/uplink data transmission, computation and display of data, and communication with the vehicle. These generic requirements are the same whether the program is to be supported using fixed or mobile facilities.

Aeronautics programs have some inherent characteristics. It is not a complex task to determine the locality of the mission since typical mission restrictions such as frequency clearance, controlled airspace, and tracking limitations exist. Factors such as mission duration can nominally be measured in hours. The nature of research activities also dictates that suppon provided be flexible, not only in scheduling, but also in how rapidly modifications can be made, to the extent of providing support of a different vehicle within minutes of notification of change.

Figure 3 shows the evolution of aeronautics requirements since the inception of the aeronautics program.' Downlink telemetry streams are in the L-band and S-band frequency spectrum, with the number of streams between 1 and 6 , and each stream running between $28 \mathrm{kbps}$ and $16.5 \mathrm{Mbps}$. The number of carricrs is between 1 and 8 . In addition to downlink telemetry, the requirement for full bandwidth downlink video in the L/S-band frequency spectrum exists. For safety of flight considerations, each stream must be recorded on an archival event.

In addition to downlink data requirements, command uplink data transmission is required. The number of data streams can vary between 0 and 4 , at rates ranging from $2 \mathrm{kbps}$ to $1 \mathrm{Mbps}$. Command uplink is in the L-band, S-band, and UHF spectrum.

For mobile applications, off-site data communications are required to transmit setup data from the fixed to the remote locations and to provide real-time data to the off-site customer. Data rate requirements range from $56 \mathrm{kbps}$ to $8 \mathrm{Mbps}$.

Acronautics programs have significant processing and display requirements. The number of research analysts at the flight test location varies from 1 to 50 . On-site processing is required to provide processed data for the generation of both graphics and alphanumeric displays for research data, in addition to space position display for range safety. Data must also be formatted and provided to the researcher/scientist for detailed postmission analysis.

Tracking system requirements must be adequate to support distances from $0.4 \mathrm{~km}$ to $250 \mathrm{~km}$. A tracking rate of $20^{\circ} / \mathrm{sec}$, slew rate of $20 \% \mathrm{sec}$, and an acceleration of $20 \% \mathrm{sec}^{2}$ are required to support missions within these distances. The antenna size will range from $2 \mathrm{~m}$ to $7 \mathrm{~m}$ with an effective isotropic radiated power (EIRP) of $60 \mathrm{dbm}$ to $90 \mathrm{dbm}$. Pointing accuracy must be within $0.1^{\circ}$.

\section{Earth Orbiter Requirements}

Earth orbiter requirements have some inherent differences when compared with aeronautics requirements. Tracking distance and accuracy requirements for earth orbiters are far greater than for aeronautics program vehicles, and the on-sitc processing and display requirements have been less in the past. The national aerospace plane (NASP) changes these classical relationships because it is both an earth orbiter and a maneuverable aeronautics vehicle.

Inherent characteristics of earth orbiter vehicles show that flexibility in supporting new requirements is not as major a driver as it is with the aeronautics program; however, the flexibility to change support from one mission to another is crucial. An important point is that we are addressing requirements for earth orbiter vehicle missions in categories of launch, launch and early orbit, and orbital. Distance requirements are limited to less than $3200 \mathrm{~km}$ with mission duration ranging from days to years.

Telemetry data requirements are for both command uplink and science data downlink. Downlink data comprised from one to four streams in the S-band and VHF spectrum with from one to three carriers. Command uplink data requirements are for one stream in the S-band frequency spectrum. Downlink data requirements per stream are $500 \mathrm{bps}$ to $15 \mathrm{Mbps}$, and for command uplink the requirement is from $250 \mathrm{bps}$ to $72 \mathrm{kbps}$.

Off-site data communications are required for all earth orbiter activities. Downlink telemetry data has been historically transmitted from the receiving station to the project operations control center (POCC). Conversely, uplink commands are sent from the POCC to the transmitting station. The real-time data rate requirements are from $500 \mathrm{bps}$ to $16 \mathrm{kbps}$, and playback data rates are 50 bps to 1024 kbps.

Earth orbiter programs have had very little on-site processing and display requirements in the past. The processing and display was done to verify commands prior to transmission to the vehicle and to format the data into blocks for transmission to the POCC and the transmission/receiving site. Space position is required for launch and early orbit for range safety, in addition to monitoring the vehicle attitude for orbit degradation. The advent of a lowcost mobile principle investigator (PI) system has the potential to change local processing and display requirements drastically.

The tracking system must be adequate to support distances from $1.5103200 \mathrm{~km}$. A tracking rate between $4^{\circ} / \mathrm{sec}$ and $5 \%$ sec, slew rate of $4 \% \mathrm{sec}$ and $5 \% \mathrm{sec}$, and an acceleration of $5 \% / \mathrm{sec}^{2}$ are required to support missions at these distances. The antenna size will range from $3 \mathrm{M}$ to $34 \mathrm{M}$ with an EIRP of $90 \mathrm{dbm}$ to $110 \mathrm{dbm}$. Pointing accuracy requirements are to be $0.01^{\circ}$.

\section{Implementation}

\section{Evolution}

The development of advanced systems for research flight test is driven by programs and projects that require support. Prior to 1986 the WATR did not have a capability to support program requirements outside the existing fixed facilities. These new requirements encouraged the WATR development team to look at creative approaches. The newest challenge was to develop a method to provide technologically advanced systems capable of supporting complex mission requirements at minimal operational cost.

The initial phase 1 proof-of-concept configuration (Fig. 4) was the support of the advanced fighter technology integration (AFTI) 
F-16 at Nellis AFB, Las Vegas, Nevada. The project required two streams of downlink pulse code modulation (PCM) data at a slant-range distance of $30 \mathrm{nmi}$ and at data rates of less than $1 \mathrm{Mbps} / \mathrm{stream}$. The requirement then was to process the data and provide this information in the form of graphic and alphanumeric displays to the mission control center (MCC) in real-time. The MCC display requirements were similar to the display requirements for support using the MCC (Fig. 5) at the DFRF facilities, with the exception of the physical number of display workstations.

The system was developed and operational 4 months after receipt of requirements, making use of systems and equipment currently under development to replace systems within the Moffett Field Flight Complex (MFFC), which includes both the Moffett Field and Crows Landing facilities. In addition to this equipment, a two-axis telemetry tracking system, a mobile C-band radar system, and a trailer were provided to the WATR by the Goddard Space Flight Center (GSFC), Wallops Flight Facility (WFF) for this activity. This completed the phase 1 configuration, shown in Fig.6 deployed at Nellis AFB, Nevada.

The system was then expanded to the phase 2 configuration (Fig. 7) to include support of L-band uplink, a remotely piloted research vehicle (RPRV) cockpit, and postflight processing to support an RPRV activity at a remote site. The downlink acquisition system was integrated into the MCC trailer; which reduced the original operational manpower requirements by two. Phase 2 completed the proof-of-concept demonstration and led to the development of an advanced mobile configuration. Figure 8 shows the phase 2 configuration deployed.

The evolution of the proof of concept led to the development of the phase 3 system (Fig. 9), based on the aeronautics requirements previously mentioned. The system will support the research flight test activities of data acquisition, data processing and display, postflight data processing, and communications, integrated in a single trailer.

\section{Capability}

The phase 3 mobile system has four major components: a telemetry tracking system, a real-time and postmission processing and display system, a communications system, and an RPRV support capability. These major systems are installed in a single semitrailer, shown in Fig. 10. Figure 11 illustrates the effective use of the trailer interior floorspace.

The trailer is an integral part of the mobile operation. Its interior dimensions are $8 \mathrm{ft}$ wide, $7 \mathrm{ft}$ high from raised floor to ceiling, and $48 \mathrm{ft}$ long, with an $18 \mathrm{ft}$ section on each side that expands out $21 / 2 \mathrm{ft}$. Gross vehicle weight rating is $50,000 \mathrm{lb}$ with a sliding tandem axle rated at $34,000 \mathrm{lb} / \mathrm{axle}$. Leveling is accomplished using four 40,000 -lb air-drive leveling jacks. To protect equipment, the trailer is equipped with an air ride suspension system and a lightning suppression system. The roof is reinforced to support the telemetry tracking system and communications antenna. The 1ton electric lift is used to install equipment in the trailer, telemetry antenna on the roof, and for wheelchair access.
The telemetry tracking system is called the mobile multifrequency tracking system (MMFTS). The system is capable of receiving or transmitting data in the $\mathrm{L}$-band, $\mathrm{S}$-band, and $\mathrm{C}$-band frequency spectrum through a $6-\mathrm{ft}$ directional antenna. Telemetry downlink is received in both frequency bands, command uplink transmitted in L-band, and downlink video in an L/S-band and $\mathrm{C}$-band frequencies. The MMFTS tracking system is a singlechannel, dual-polarization system capable of switching tracking receivers within band or between bands without interrupting the track or the received data. The telemetry receiving system consists of eight receivers and four combiners, with four receivers being designated for the horizontal channel and four for the vertical channel. The television receiving system consists of two dual-channel receiver/combiners. The system will be stowed in the rear of the trailer, fully assembled for transportation, as shown in Fig. 11.

The real-time processing and display system, called the parallel telemetry and processing system (PTAPS, Fig. 12) is a modular data acquisition and control concept. In the modular concept (Fig. 13), separate telemetry data streams at synchronous or asynchronous bit rates are received by separate 68000 -series stream processors. Each stream processor carries out various front-end processing tasks and performs vectored transfers of complete data frames to resident memory-mapped tables in associated random access memory (RAM) modules.

By using separate high-speed stream processors, various types of preprocessing operations can be accomplished simultaneously in real time. These include data compression, data concatenation, bit mapping, time and ID tagging, fixed-to-floating point conversion, engineering unit conversion, and limit checking. Additional 68000-series processors perform such functions as strip chart control, graphics generation, alphanumeric display generation, map generation, digital-to-analog conversion, data distribution, bulk data storage and retrieval, and real-time executive and file management tasks. High-speed arithmetic and array processing units are also provided for handling complex mathematical operations and matrix or vector manipulations.

The communications system is configured for both RF and ground communications. The RF system has two UHF and two VHF tunable transceivers connected to a uniquely designed compact antenna that permits operation in both frequency bands using a common radiating element. The ground system supports 10 circuits currently designated as UHF-1, UHF-2, VHF-1, VHF-2, hot microphone, RPRV, LOCAL, trailer maintenance, and two spares. These circuits are available on nine stations with two headsets each and disbursed throughout the trailer.

The RPRV capability allows for remote operation of an unmanned research vehicle. The ground-based cockpit receives downlink telemetry data that has been decoded and processed to be displayed on the instrument panel. Pilot inputs from the cockpit are encoded and transmitted to the vehicle to close the control loop. The cockpit is also capable of simulating the stick and rudder forces to give the sensation of being in an actual vehicle. Downlink video is displayed on a CRT to simulate an out-the-nose view from the cockpit. 
The capability described is highly integrated with an automated setup and requires an operational staff of two highly qualified technicians who are also responsible for system maintenance, assembly, setup, and disassembly for transport. This method of operation provides an advanced capability at low cost for support of the agency aeronautics program.

\section{Growth Projection}

The mobile research flight test support capability will continue to evolve for the support of additional requirements. The phase 4 configuration will consist of the addition of a larger antenna. This addition will expand the support capability for the agency's earth orbiter program. The development of a low-cost PI system will also contribute toward further advancement of the capability.

The growth of this capability is dependent on these two concepts: integration and automation. Physical size is directly dependent on the amount of integration accomplished. Automation will allow the system to be electronically set up for operation by a remote database. Maximum integration and automation will allow the operation to be successfully maintained with a minimum of on-site staff. By addressing these issues the NASA Western Aeronautical Test Range will continue to be successful in providing a cost-effective, technologically superior method to support the aeronautics and space requirements of the agency.

\section{Concluding Remarks}

The WATR mobile research flight test support capability satisfies a unique sector of requirements for both the aeronautics and earth orbiter programs of the agency. Its inherent size and capability illustrate a new and novel approach in the area of ground-based experimental facility techniques. Its modular design allows for rapid response to programmatic support requirements. Its physical configuration allows for maximum support with minimal staffing. The sum of its unique attributes provides an effective, efficient, technologically superior support capability for the agency's aeronautics and space program.

\section{Reference}

${ }^{1}$ Moore, Archie L., "The Western Aeronautical Test Range of NASA Ames Research Center," NASA TM-85924, 1985.

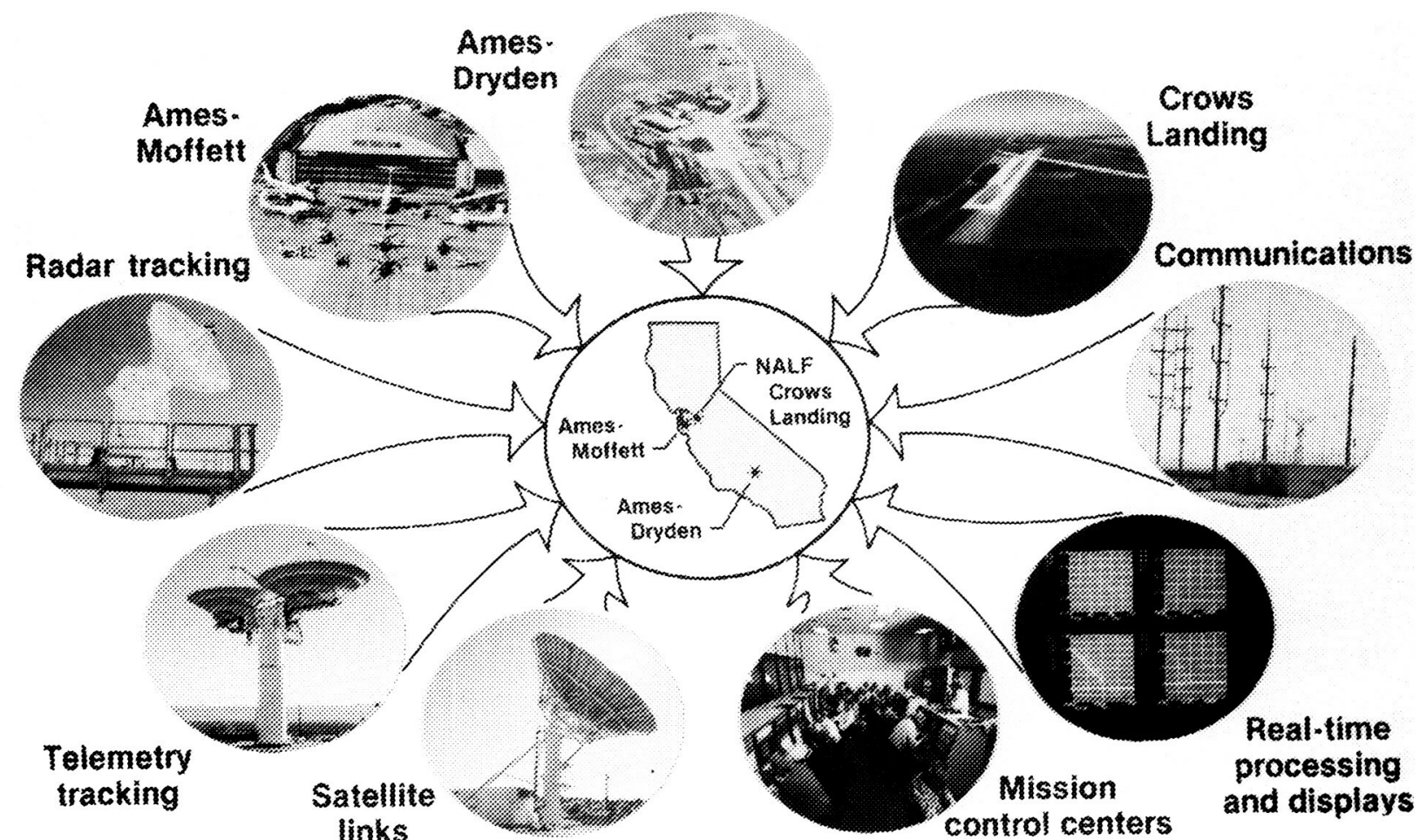

AD86-330

Fig. 1 Western Aeronautical Test Range. 


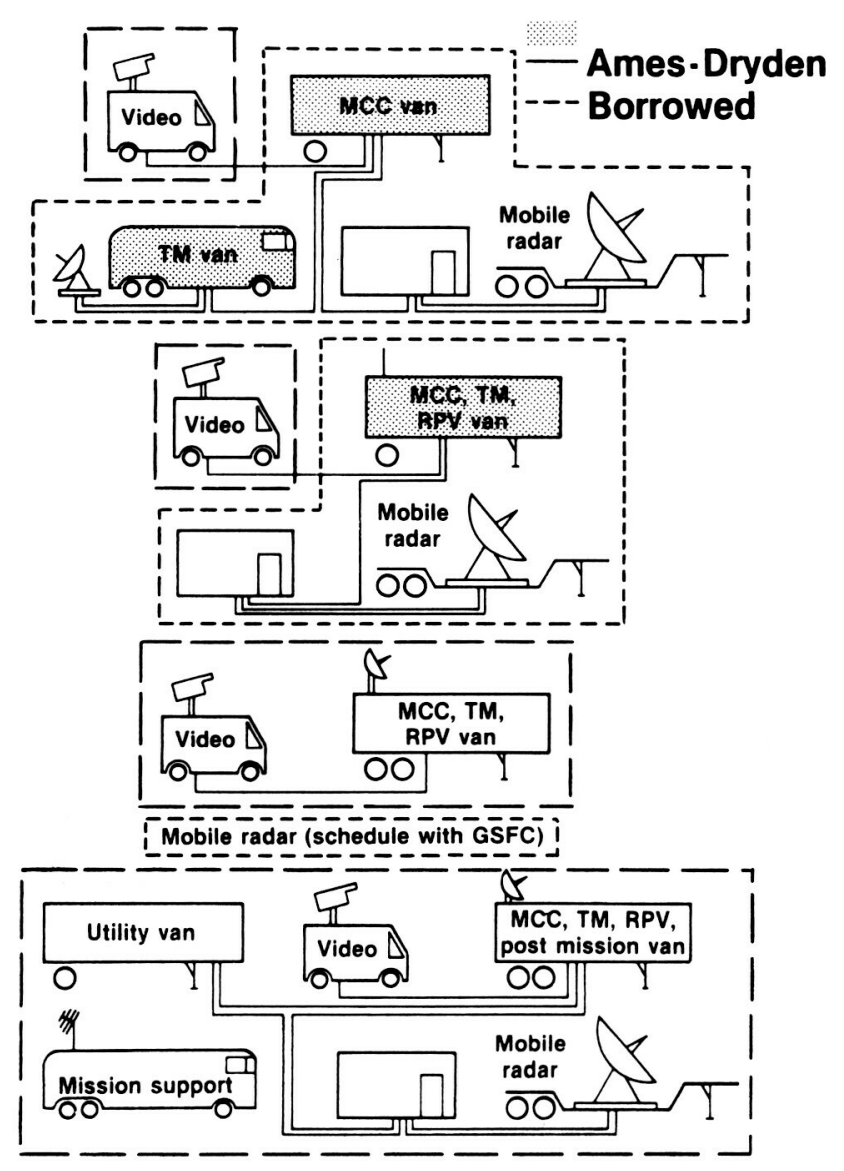

Phase 1

(AFTI/F-16 Nellis AFB)

May 1986

ORIGINAI PAGE IS

OE POOR QUALITY

Phase 2

(AVC China Lake)

August 1986/

October 1986

Phase 3

September 1988

Phase N

1994

Fig. 2 WATR mobile configuration evolution.

AD87-053a

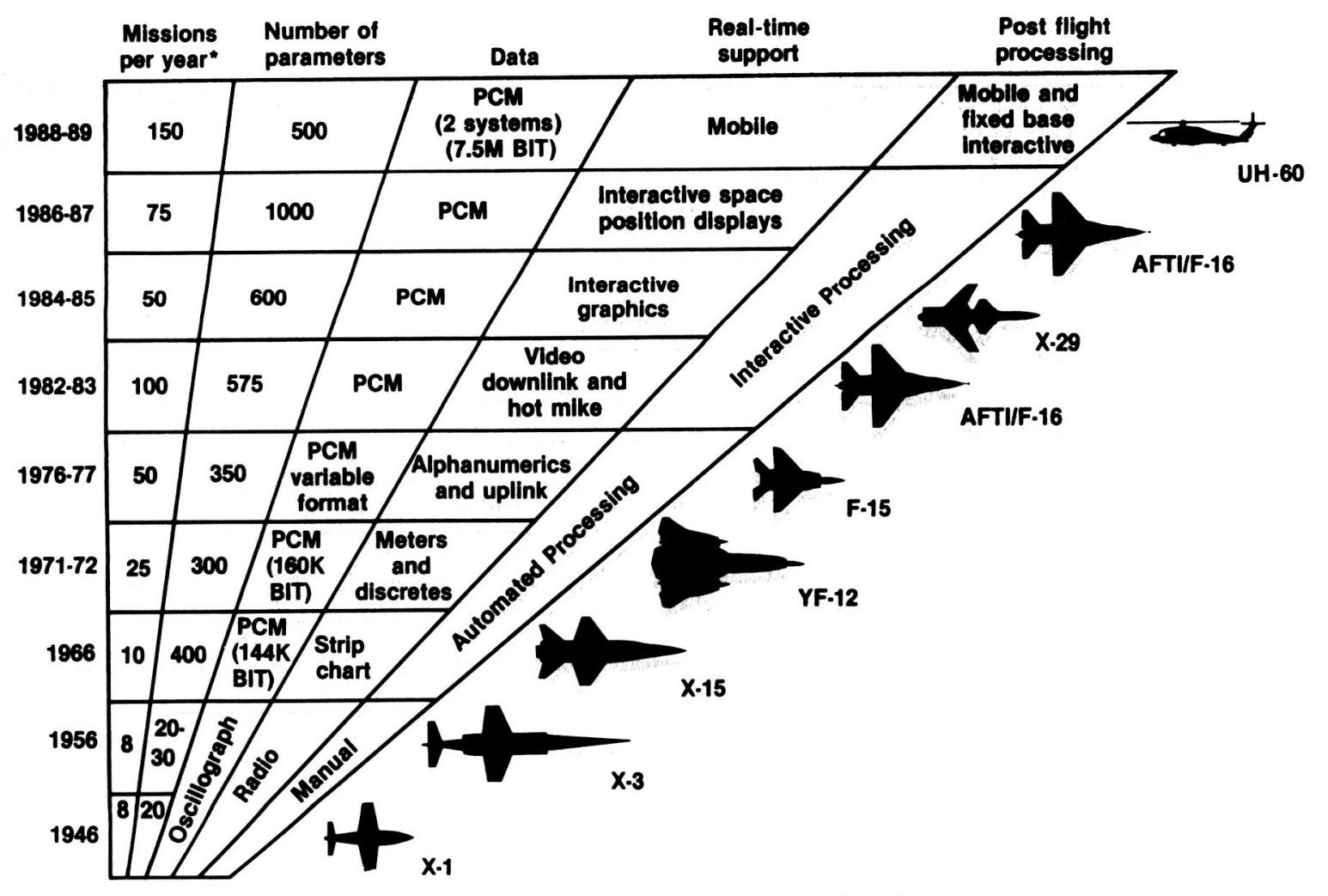

"For vehicle depicted, Includes filghts, combined systems tests, and engine runs

Fig. 3 Evolution of aeronautical program requirements. 


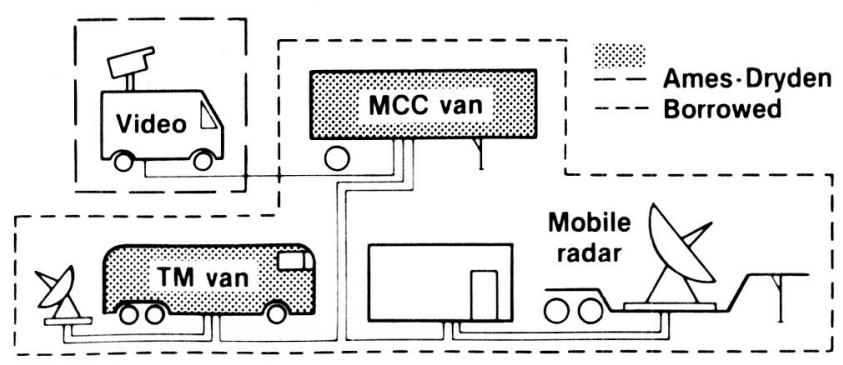

(AFTI/F-16 Nellis AFB)

Fig. 4 WATR mobile configuration, phase 1.

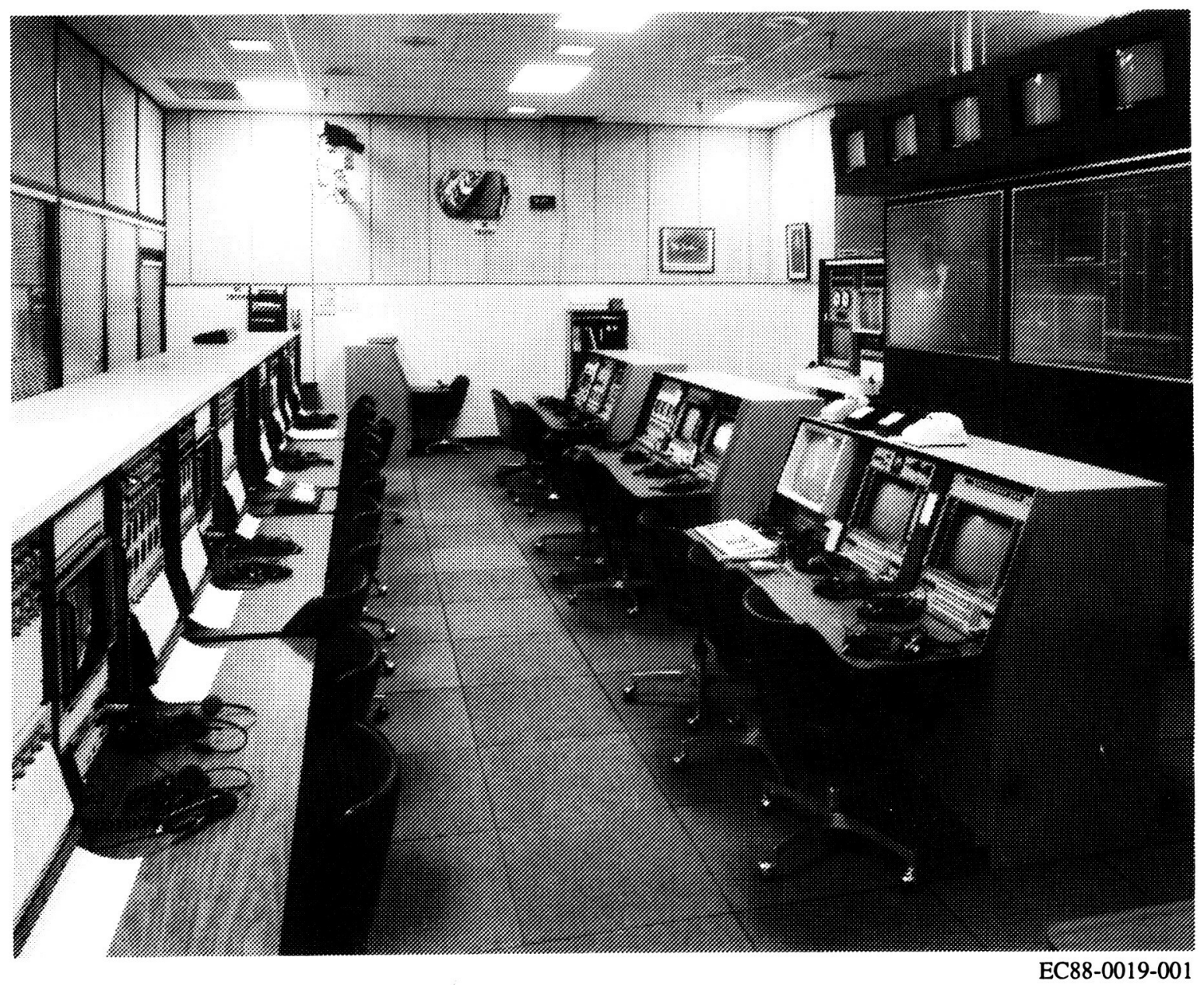

Fig. 5 Blue mission control center. 


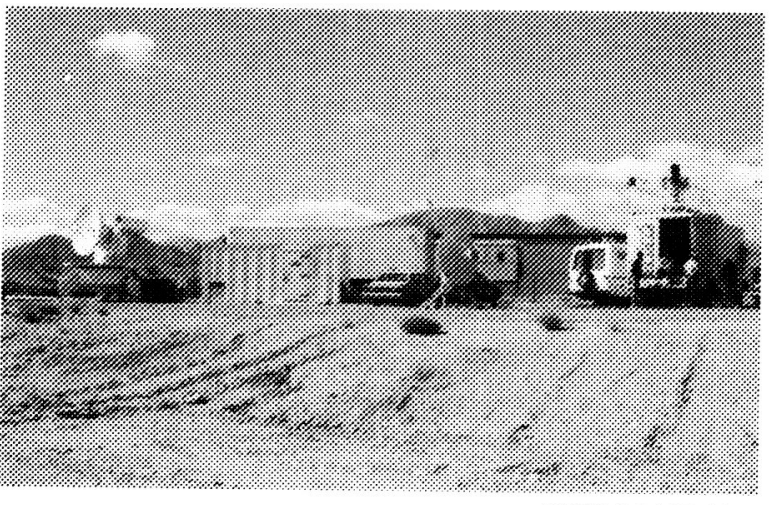

ECN 33456-007

Fig. 6 Phase 1 configuration deployed at Nellis AFB, Nevada.

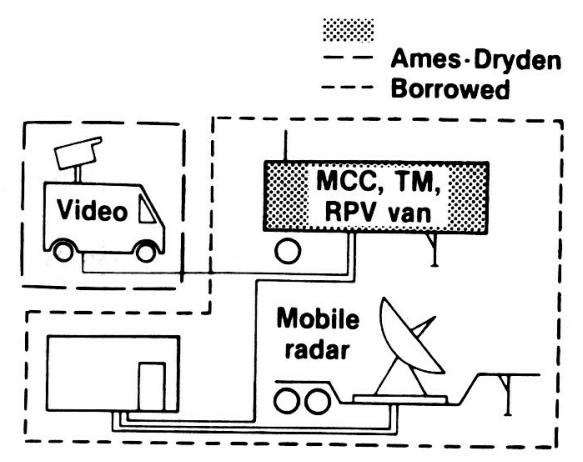

(AVC China Lake)

8099

Fig. 7 WATR mobile configuration, phase 2.

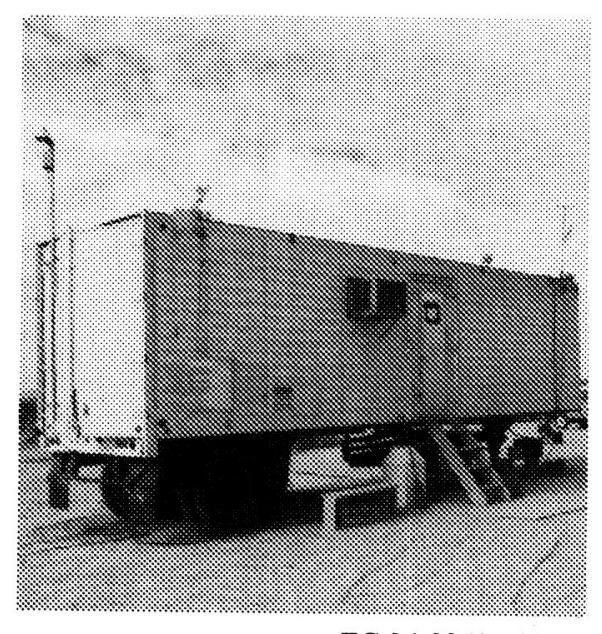

EC 86-33605-004

Fig. 8 Phase 2 configuration deployed.

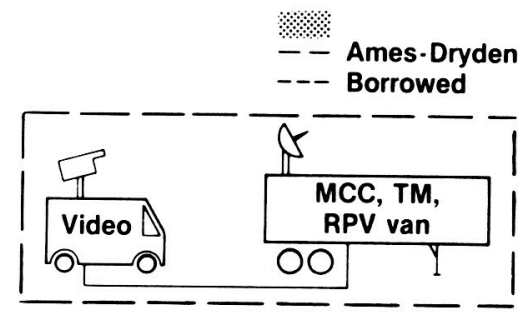

Mobile radar (schedule with GSFC)

Fig. 9 WATR mobile configuration, phase 3.

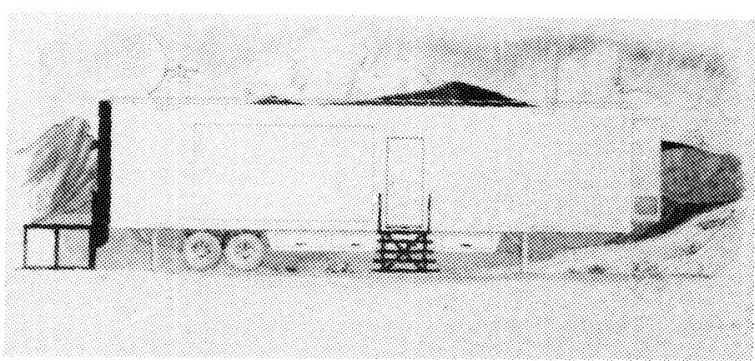

EC 88-0001-001

Fig. 10 Artist's conception of the phase 3 mission operations trailer. 


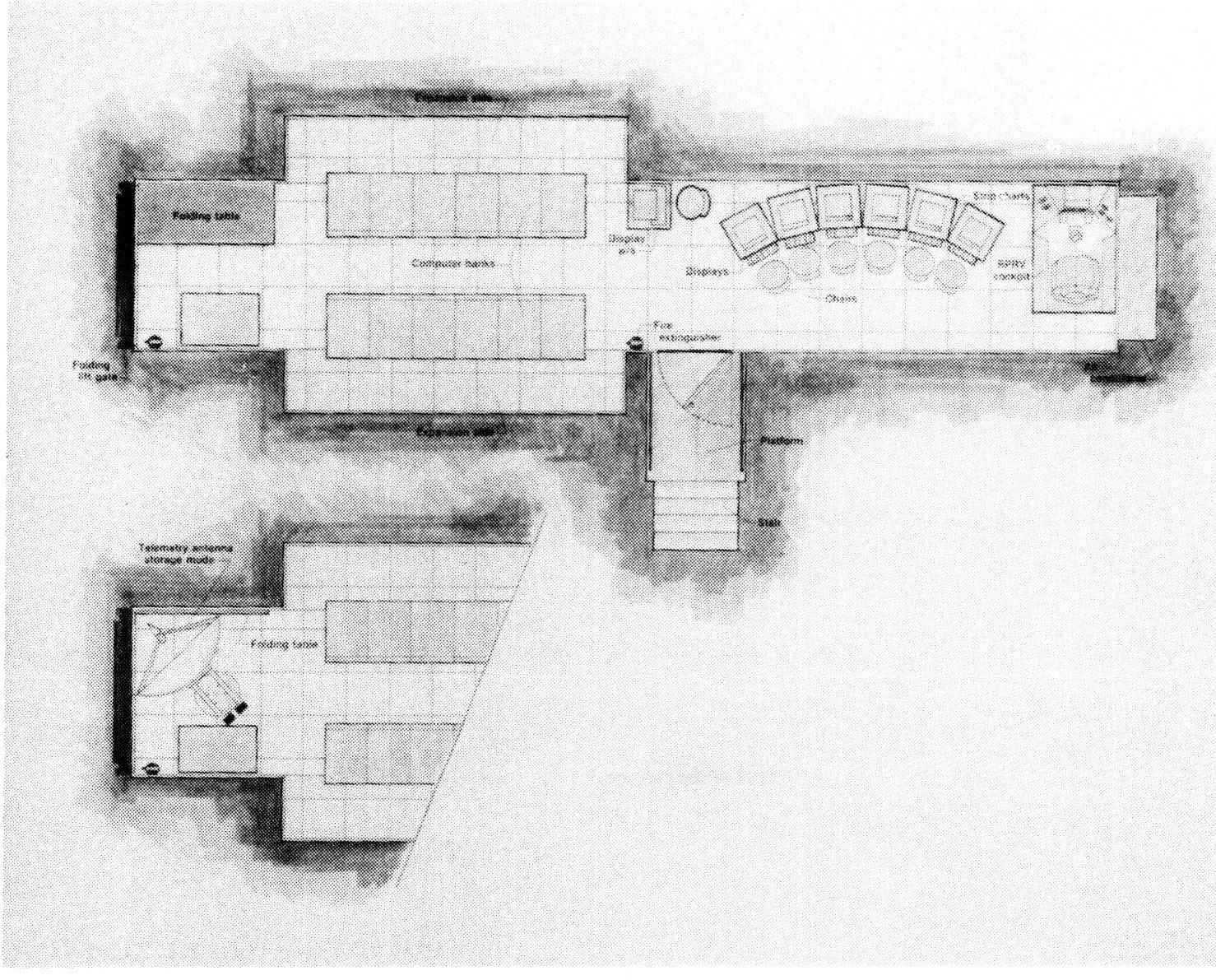

Fig. 11 Artist's conception of mobile system layout.

EC 88-0001-003

\section{ig. 11 Artist's conception of mobile system layout.}

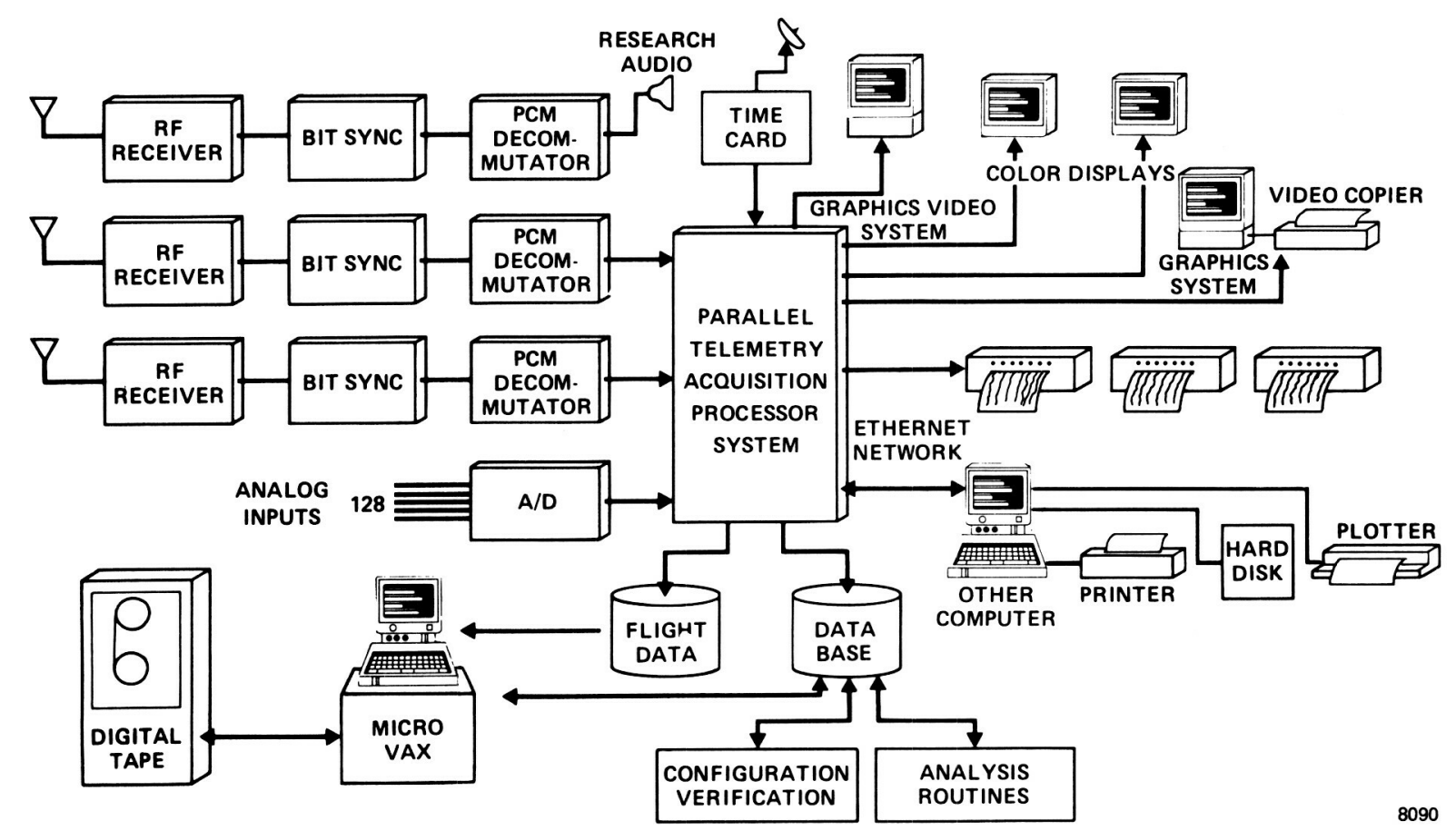

Fig. 12 Current PTAPS configuration for mobile operations. 


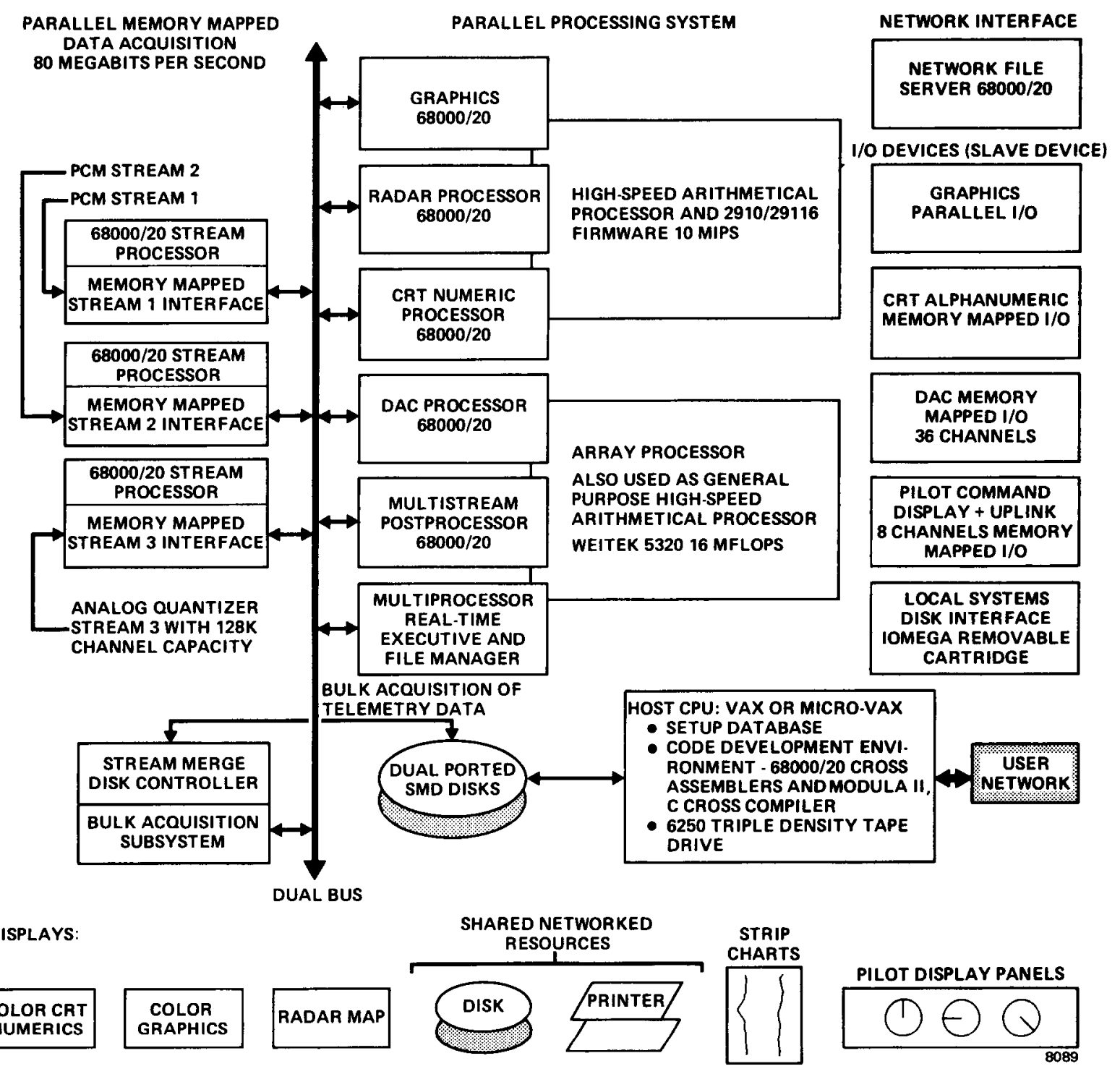

Fig. 13 Parallel telemetry and processing system (PTAPS). 


\begin{tabular}{|c|c|c|c|c|}
\hline \multicolumn{5}{|c|}{ Report Documentation Page } \\
\hline $\begin{array}{l}\text { 1. Report No. } \\
\text { NASA TM-100428 }\end{array}$ & \multicolumn{2}{|c|}{ 2. Government Accoscion No. } & \multicolumn{2}{|c|}{ 3. Recipient's Catalog No. } \\
\hline \multicolumn{3}{|l|}{ 4. Titto and Subritle } & \multicolumn{2}{|l|}{$\begin{array}{l}\text { 5. Report Date } \\
\text { May } 1988\end{array}$} \\
\hline \multicolumn{3}{|c|}{$\begin{array}{l}\text { Development of a Mobile } \\
\text { Research Flight Test Support Capability }\end{array}$} & \multicolumn{2}{|c|}{\begin{tabular}{|l} 
6. Performing Organization Code \\
\end{tabular}} \\
\hline \multirow{2}{*}{\multicolumn{3}{|c|}{$\begin{array}{l}\text { 7. Author(s) } \\
\text { Donald C. Rhea and Archie L. Moore }\end{array}$}} & \multicolumn{2}{|l|}{ H-1456 } \\
\hline & & & \multicolumn{2}{|c|}{$\begin{array}{l}\text { 10. Work Unit No. } \\
\text { 314-50, 314-60 }\end{array}$} \\
\hline \multicolumn{3}{|c|}{ 9. Performing Organization Name and Addreas } & \multirow{2}{*}{\multicolumn{2}{|c|}{ 11. Contract or Grant No. }} \\
\hline \multirow{2}{*}{\multicolumn{3}{|c|}{$\begin{array}{l}\text { NASA Ames Research Center } \\
\text { Dryden Flight Research Facility } \\
\text { P.O. Box 273, Edwards, CA } 93523-5000\end{array}$}} & & \\
\hline & & & \multirow{2}{*}{\multicolumn{2}{|c|}{$\begin{array}{l}\text { 13. Type of Report and Period Covered } \\
\text { Technical Memorandum }\end{array}$}} \\
\hline \multirow{2}{*}{\multicolumn{3}{|c|}{$\begin{array}{l}\text { 12. Sponsoring Agency Nemo and Addrose } \\
\text { National Aeronautics and Space Administration } \\
\text { Washington, DC } 20546\end{array}$}} & & \\
\hline & & & 14. Sponsoring $A$ & ey Code \\
\hline \multicolumn{5}{|c|}{$\begin{array}{l}\text { Prepared for presentation as AIAA-88-2087 at the 4th Flight Test Conference, San Diego, California, } \\
\text { May } 18-20,1988 .\end{array}$} \\
\hline \multicolumn{5}{|l|}{ 16. Abstract } \\
\hline \multicolumn{5}{|c|}{$\begin{array}{l}\text { This paper presents the approach taken by the NASA Western Aeronautical Test Range (WATR) of the Ames } \\
\text { Research Center (ARC) to develop and utilize mobile systems to satisfy unique real- time research flight test } \\
\text { requirements of research projects such as the advanced fighter technology integration (AFTI) F-16, YAV- 8B } \\
\text { Harrier, F-18 high-alpha research vehicle (HARV), XV-15, and the UH-60 Black Hawk. The approach taken } \\
\text { is cost-effective, staff efficient, technologically current, and provides a safe and effective research flight } \\
\text { test environment to support a highly complex set of real-time requirements including the areas of tracking } \\
\text { and data acquisition, communications (audio and video) and real-time processing and display, postmission } \\
\text { processing, and command uplink. The development of this capability has been in response to the need for } \\
\text { rapid deployment at varied site locations with full real-time computations and display capability. This paper } \\
\text { will discuss the requirements, implementation and growth plan for mobile systems development within the } \\
\text { NASA Western Aeronautical Test Range. }\end{array}$} \\
\hline \multicolumn{2}{|c|}{$\begin{array}{l}\text { 17. Key Words (Suggested by Author(s)) } \\
\text { Mission control center; Mobile; Real-time processing } \\
\text { and display; Telemetry tracking; Western Aeronautical } \\
\text { Test Range }\end{array}$} & $\begin{array}{l}\text { 18. Dist } \\
\text { Un }\end{array}$ & -Unlimited & ect category 04 \\
\hline $\begin{array}{l}\text { 19. Security Classif. (of this report) } \\
\text { Unclassified }\end{array}$ & $\begin{array}{l}\text { 20. Security Classif. lof t } \\
\text { Unclassified }\end{array}$ & is pagel & $\begin{array}{l}\text { 21. No. of pages } \\
10\end{array}$ & $\begin{array}{l}\text { 22. Price } \\
\text { A02 }\end{array}$ \\
\hline
\end{tabular}

